\title{
"HIGH-RISK" HOST CELL PROTEINS (HCPs): A MULTI-COMPANY COLLABORATIVE VIEW
} \author{
Patricia Connolly ${ }^{12}$ \\ ${ }^{1}$ GlaxoSmithKline \\ ${ }^{2}$ Regeneron Pharmaceuticals Inc \\ ${ }^{3}$ Merck \& Co Inc \\ ${ }^{4}$ AbbVie Inc \\ ${ }^{5}$ Immunogen Inc \\ ${ }^{6}$ Janssen Pharmaceutical Companies of Johnson and Johnson \\ ${ }^{7}$ Sanofi SA \\ ${ }^{8}$ Biogen Inc \\ ${ }^{9}$ Pfizer Inc \\ ${ }^{10}$ Bristol-Myers Squibb Co \\ ${ }^{11}$ Boehringer Ingelheim Pharma GmbH \\ ${ }^{12}$ BioPhorum
}

Marisa Jones ${ }^{1}$, Nisha Palackal ${ }^{2}$, Fengqiang Wang ${ }^{3}$, Georgeen Gaza-Bulseco ${ }^{4}$, Karen Hurkmans $^{4}$, Yiwei Zhao ${ }^{5}$, Carmelata Chitikila ${ }^{6}$, Séverine Clavier ${ }^{7}$, Suli Liu $^{8}$, Emily Menesale $^{8}$, Nicole Schonenbach ${ }^{9}$, Satish Sharma ${ }^{10}$, Thomas Waerner ${ }^{11}$, Lei Zhang ${ }^{10}$, and

October 14, 2020

\begin{abstract}
Host cell proteins (HCPs) are process-related impurities that may co-purify with biopharmaceutical drug products. Within this class of impurities there are some that are more problematic. These problematic HCPs can be considered high-risk and can include those that are immunogenic, biologically active, or enzymatically active with the potential to degrade either product molecules or excipients used in formulation, and often are difficult-to-purify. Why should the biopharmaceutical industry worry about these high-risk host cell proteins? What approach could be taken to understand the origin of this co-purification and to deal with these high-risk HCPs? To answer these questions, the BioPhorum Development Group (BPDG) HCP Workstream initiated a collaboration among its 26-company team with the goal of industry alignment around high-risk HCPs. A sub team was formed, in which the members performed literature searches and discussed the information available around this topic. A survey to the BPDG HCP Workstream team members led to team discussions and insights into a list of frequently seen problematic HCPs. These HCPs were further classified based on their potential impact into different risk categories that could be beneficial to the biopharmaceutical industry for targeted monitoring of those HCP impurities in CHO-produced biologics to minimize risk to product quality, safety, and efficacy.
\end{abstract}

\section{Hosted file}

BPDG HIGH-RISK HOST CELL PROTEINS- A MULTI-COMPANY COLLABORATIVE VIEW Paper - Submission 14 Oct 2020. pd available at https://authorea.com/users/367042/articles/486630--high-risk-host-cellproteins-hcps-a-multi-company-collaborative-view 